\title{
CLINICAL STUDY OF THE CHANGE OF PH LEVEL IN THE SUPRAGINGIVAL PLAQUE IN CHILDREN AFTER TAKING HOMEOPATHIC REMEDIES
}

\author{
A. Pomakova1', N. Gateva², K. Hristov² \\ ${ }^{1}$ Department of Paediatric Dentistry, Faculty of Dental Medicine, Medical University - Varna, Bulgaria \\ ${ }^{2}$ Department of Paediatric Dentistry, Faculty of Dental Medicine, Medical University - Sofia, Bulgaria
}

\begin{abstract}
Objective: There are numerous publications on the parameters of conventional medications, which contribute to their cariogenic and erosive potential. Little is known about the homeopathic remedies (HR) and the changes in the oral cavity they lead to, especially during childhood. Material and methods: The study involved 25 children (5-9 years of age). It monitored the change in plaque $\mathrm{pH}$ level after intake of three frequently used homeopathic remedies in five consecutive weeks. The $\mathrm{pH}$ level values were measured after the administration of the remedies, without HR intake, and after rinsing with $10 \%$ sucrose solution. Five groups were formed - two controls and three groups with results from the tested HR. Results: A drop in the plaque $\mathrm{pH}$ level was observed after intake of all HR and in all tested individuals. The biggest decrease was observed at the 15th minute for all $H R$. At the 30th minute the greatest decrease was observed with the second remedy, and at 60 th minute - with the first and second. Conclusions: A dramatic decrease in the plaque $\mathrm{pH}$ level was observed after intake of each studied remedy. In many cases the drop was below the critical value of $\mathrm{pH}=5.5$. The low plaque $\mathrm{pH}$ values were maintained even at the 60 th minute after the start of the study.
\end{abstract}

Key words: dental plaque, homeopathic treatment, homeopathic remedies, plaque $\mathrm{pH}$, tooth decay

Corresponding author: Dr. Krasimir Mitkov Hristov, Department of Paediatric Dentistry, Faculty of Dental Medicine, 1 G. Sofiyski Street, Medical University, 1431 Sofia, Bulgaria, tel.: +359883411743, E-mail:dr.hristov12@gmail.com

RECEIVED: 9 July 2019, ACCEPTED: 17 July 2019

\section{INTRODUCTION}

A significant number of studies have proven the risk of frequent use of conventional sugar-containing medications in relation to the caries process, especially in childhood [1-6]. The factors determining the cariogenic potential of the conventional medications are the sucrose content and the acidic nature of the drug $[7,8]$. The frequency, dose and way of administration of the medications are of significant importance, too [4]. The use of sweetened medications among children is widespread [9-11].

In recent years, consumer demands for $100 \%$ natural and harmless products have risen significantly. This is one of the reasons why the number of patients using complementary and alternative medicine (CAM) is rising [12]. Homeopathy is one of the most popular forms of CAM nowadays [13].

Homeopathic remedies, like conventional paediatric drugs, contain sugars and acids. Moreover, they 
have specific rules for administration - at multiple times during the day, between meals, they are placed for a long time under the tongue and are not to be used alongside with fluoride toothpastes [14-17]. Very often one of the doses is given in the evening at bedtime [17]. All of these factors contribute to the increased risk of developing a carious process related to the frequent intake of HR due to the sugars and acids present in them.

This study aims to assess the dynamics of the changes in the plaque $\mathrm{pH}$ level in children after taking three of the most frequently used homeopathic remedies. Our hypothesis is that the intake of these medications, due to their sugar and acid content, leads to a rapid drop in the plaque $\mathrm{pH}$ under its critical values, which is maintained for a long period of time.

\section{MATERIAL AND METHODS}

Twenty-five children (5 to 9 years of age) took part in this study. The study was approved by the Research Ethics Committee, Faculty of Dentistry, Medical University - Varna, Bulgaria. Written informed consent for the participation in the clinical study was obtained from their parents. The change in the plaque $\mathrm{pH}$ level was monitored after taking three of the most frequently used homeopathic remedies (according to data from our survey). The first remedy was homeopathic pillules for stimulation of the immune system (remedy № 1). These pillules contain as active ingredients Anas Barbariae Hepatis and Cordis Extractum (extract of Muscovy duck liver and heart) and inactive ingredients sucrose and lactose. They are usually taken two to three times daily 15 minutes prior to or an hour after meals. The second remedy is viscous homeopathic cough syrup (remedy № 2). Active ingredients in $100 \mathrm{~g}$ syrup are antimonium tartaricum, bryonia, coccus cacti, drosera, ipecacuanha, pulsatilla, rumex crispus, spongia tosta, sticta pulmonaria, and the non-medicinal ingredients are purified water, sucrose $(11.25 \mathrm{~g} / 15 \mathrm{ml})$ honey, citric acid monohydrate, and sodium benzoate. It is usually taken three to five times daily between meals. The third HR is in the form of granules with pain-relieving action and often used for discomfort associated with teething (remedy № 3). This product contains as active ingredients camomile $3 X$ to $30 X-3 C$ to $30 C$ and inactive ingredients lactose and sucrose. Three to five granules are taken unlimited times during the day.

The collection of plaque was done using a sterile instrument by scraping the area of the gingival third of the vestibular surface of the molars. The collected volume of plaque was the size of a pin head $(1 \mathrm{mg})$. It was then dissolved in $20 \mathrm{ml}$ of distilled water, af- ter which the $\mathrm{pH}$ of the solution was measured using a colorimetric method. This involved the use of two types of $\mathrm{pH}$ test strips: PANPEHA strips, Schleicher \& Schüll $\mathrm{GmbH}$, with 0,2 accuracy and $\mathrm{pH}$-strip with accuracy 1 . The strips were dipped in the solution and the change in their colour was monitored, measuring the change in the $\mathrm{pH}$ of the solution.

The children were in good general health. At the time, they were not undergoing any medication treatment. The study was carried out on a chosen day of the week for five consecutive weeks.

The study monitored the changes in supragingival plaque $\mathrm{pH}$ values in children. The baseline $\mathrm{pH}$ was measured, as well as the $\mathrm{pH}$ at the 15th, 30th and 60th minute after the intake of the respective homeopathic remedy. The reasons to register change in plaque $\mathrm{pH}$ at these time intervals were (1) existing knowledge about the buffer capacity of the saliva, (2) the sharp drop in the plaque $\mathrm{pH}$ under critical levels after taking simple carbohydrates and (3) its slow increase to the baseline levels, requiring 15-40 minutes (demonstrated by the Stephan curve). The aim was a better presentation of the dynamics of the change in $\mathrm{pH}$, as well as the possible role as a risk factor for the development of a carious process based on the continuous acidity, which develops after intake of a homeopathic remedy containing sugars and/or acids.

The test was performed in the morning, between 8 and 11 o'clock, in order to avoid the circadian rhythm effects. The children did not brush their teeth on that day and had not taken food or drinks for at least one hour prior to the start of the study. The same children took part in the study for its whole duration.

On the first day of the study, the plaque $\mathrm{pH}$ value was measured at the respective time intervals without remedy intakes. In this way, the values of the plaque $\mathrm{pH}$, serving as control, were determined (control group - group 1). In the second week, on the set day, after measuring the baseline plaque $\mathrm{pH}$ value, one dose of pillules of remedy № 1 was administered under the tongue until complete dissolution. Then the $\mathrm{pH}$ value was measured at the 15th, 30th and 60th minute. The registered values of the plaque $\mathrm{pH}$ after administering remedy 1 comprised data determined as group 2. In the third week on the set day, the same scheme was repeated as in the second week but one dose of $15 \mathrm{ml}$ from the homeopathic syrup was administered (remedy № 2). The registered values comprised the data for group 3 . On the set day of the fourth week, 5 granules of homeopathic remedy № 3 were placed and held under the tongue until they were fully dissolved. The measured plaque $\mathrm{pH}$ values comprised the results for group 4. On the 
set day during the fifth week and again repeating the described scheme, the children rinsed their mouths with $10 \%$ sucrose solution for 1 minute. The registered values in the plaque $\mathrm{pH}$ were recorded and comprised the data for group 5, which served as a second control group.

After the study, during each of the weeks, the children were asked to brush their teeth with a toothbrush and fluoride toothpaste.

All results (from the five measurements and the respective time intervals) were recorded on a personal card for each volunteer and then subjected to statistical analysis. Based on the values recorded for each sample, the mean value of the plaque $\mathrm{pH}$ was calculated as a baseline and then at the 15th, 30 th and 60th minute for each of the groups. The difference in the plaque $\mathrm{pH}$ values between the separate control periods for each sample and in each group was calculated. These differences were used to calculate the mean drop value in the plaque $\mathrm{pH}$ for each time interval and for each of the studied groups. The results were subjected to statistical analysis to test them for reliability.

\section{RESULTS}

Based on the recorded values of the supragingival plaque $\mathrm{pH}$ at the respective time intervals for all studied groups and for each patient, the number of drops was calculated (and also \%) for the respective time intervals for each of the five groups. The results are shown in Table 1.

At the 15th minute there was a drop in the plaque $\mathrm{pH}$ values for all $25(100 \%)$ studied samples and in all studied groups with the exception of the samples from the control group (group 1), where no change was recorded in the plaque $\mathrm{pH}$ values. At the 30th minute a tendency of slow increase in the values was observed but the measured plaque $\mathrm{pH}$ values remained below the recorded baseline values in almost all of the groups with one exception in group $5(\mathrm{n}=$ $24,96.0 \%$, Table 1). At the 60th minute, the drop in the plaque $\mathrm{pH}$ values was maintained in most samples (Table 1). This drop was observed in 25 of the samples $(100 \%)$ in group 3 , i.e. there were no cases with recovered baseline plaque $\mathrm{pH}$ value. The highest number of samples with recovered $\mathrm{pH}$ was observed in group 5-6 samples in total. We found only 1 sample with recovered plaque $\mathrm{pH}$ value in group 2 and two samples with recovered baseline value in group 4 (Table 1).

Table 2 shows the mean drop values in the plaque $\mathrm{pH}$ for all groups at the respective time periods.

The highest mean drop value in the plaque $\mathrm{pH}=-2,24$ was observed at the 15th minute in group 3 (Table 2). Group 2 came second with a mean drop value of the $\mathrm{pH}=-1,76$, followed by group 4 with mean drop $\mathrm{pH}$ value $-1,7$. The lowest mean drop plaque $\mathrm{pH}$ value was found among the samples in group $5-1,54$. The

Table 1. Samples with registered drop in plaque $\mathrm{pH}$ for each group at the respective time intervals (by number and \% of samples with drop)

\begin{tabular}{|l|c|c|c|c|c|c|}
\hline \multirow{2}{*}{ Group } & \multicolumn{2}{|c|}{ 15th minute } & \multicolumn{2}{c|}{ 30th minute } & \multicolumn{2}{c|}{ 60th minute } \\
\cline { 2 - 7 } & $\begin{array}{c}\text { Number of } \\
\text { samples ( } \mathrm{n} \text { ) }\end{array}$ & $\begin{array}{c}\text { \% samples } \\
\text { with drop }\end{array}$ & $\begin{array}{c}\text { Number of } \\
\text { samples }(\mathrm{n})\end{array}$ & $\begin{array}{c}\text { \% samples } \\
\text { with drop }\end{array}$ & $\begin{array}{c}\text { Number of } \\
\text { samples ( } \mathrm{n} \text { ) }\end{array}$ & $\begin{array}{c}\text { \% samples } \\
\text { with drop }\end{array}$ \\
\hline 1-without HR (control) & $\mathrm{n}=0$ & 0.0 & $\mathrm{n}=0$ & 0.0 & $\mathrm{n}=0$ & 0.0 \\
\hline 2- pillules & $\mathrm{n}=25$ & 100.0 & $\mathrm{n}=25$ & 100.0 & $\mathrm{n}=24$ & 96.0 \\
\hline 3- syrup & $\mathrm{n}=25$ & 100.0 & $\mathrm{n}=25$ & 100.0 & $\mathrm{n}=25$ & 100.0 \\
\hline 4- granules & $\mathrm{n}=25$ & 100.0 & $\mathrm{n}=25$ & 100.0 & $\mathrm{n}=23$ & 92.0 \\
\hline 5- sucrose (control) & $\mathrm{n}=25$ & 100.0 & $\mathrm{n}=24$ & 96.0 & $\mathrm{n}=19$ & 76.0 \\
\hline
\end{tabular}

Table 2. Mean drop values in the plaque $\mathrm{pH}$ at different time intervals in all groups

\begin{tabular}{|l|c|c|c|c|c|c|c|}
\hline \multirow{2}{*}{ Group } & \multicolumn{7}{|c|}{ Mean level of drop in $\mathrm{pH}$ of the plaque } \\
\cline { 2 - 8 } & Baseline & 15th min & Difference & 30th min. & Difference & 60th min & Difference \\
\hline Group 1 & 6.3 & 6.30 & 0.00 & 6.30 & 0.00 & 6.30 & 0.00 \\
\hline Group 2 & 6.56 & 4.80 & -1.76 & 5.08 & -1.48 & 5.46 & -1.10 \\
\hline Group 3 & 6.52 & 4.28 & -2.24 & 4.80 & -1.72 & 5.52 & -1.00 \\
\hline Group 4 & 6.4 & 4.70 & -1.70 & 5.20 & -1.20 & 5.62 & -0.78 \\
\hline Group 5 & 6.32 & 4.78 & -1.54 & 5.32 & -1.00 & 5.82 & -0.50 \\
\hline
\end{tabular}


mean drop value in the $\mathrm{pH}$ in group 1 was negligible at the respective time intervals.

The same tendency is seen at the 30th minute. The highest mean value of drop in the plaque $\mathrm{pH}$ was observed in group $3(-1,72)$ and the lowest mean drop plaque $\mathrm{pH}$ value was in group 5 (-1, Table 2$)$.

There was a small difference in the distribution of the mean drop values in the plaque $\mathrm{pH}$ at 60 th minute. At that time interval the mean drop plaque $\mathrm{pH}$ value in group 2 was the highest $\mathrm{pH}=-1,1$, followed by group 3 with $\mathrm{pH}=-1$ and group 4 and 5 , respectively with $-0,8$ and $-0,7$ (Table 2). The changes in the mean drop values of the plaque $\mathrm{pH}$ within the periods of the experiment for all groups are shown in Diagram 1.

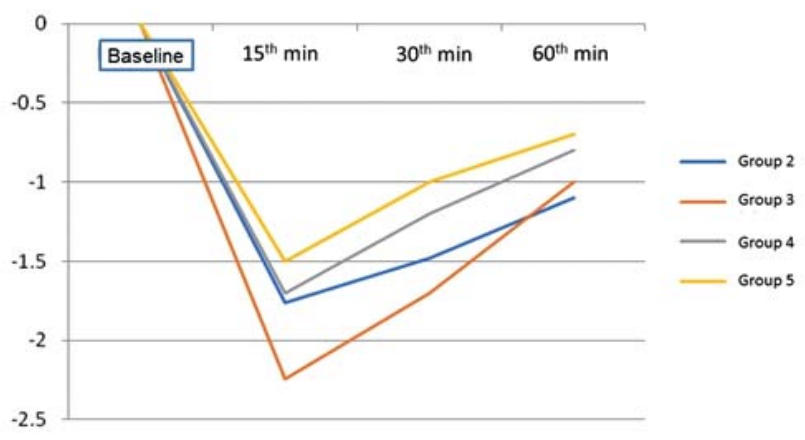

Diagram 1. Changes in the mean drop value of the plaque $\mathrm{pH}$ at the 15th, 30th and 60th minute in the experimental groups
We compared all the groups with a registered drop by comparing the mean drop values of the plaque $\mathrm{pH}$ and we looked for significance of the differences (Table 3). Group 1 (first control group) was not included in the comparison due to the absence of a registered drop in the plaque $\mathrm{pH}$ values at the control time intervals. The comparison was made between the rest of the groups and the second control group (group 5).

At the 15th minute a statistically significant difference was established in the mean drop values in the plaque $\mathrm{pH}$ between group 2 and group $3(\mathrm{p}=0.000$, Table 3$)$, between group 3 and group $4(p=0.000)$ and between group 3 and group $5(p=0.000$, Table 3 ). Among the other groups the difference in the mean drop values in the plaque $\mathrm{pH}$ is not statistically significant $(p>0.05$, Table 3$)$.

At the 30th minute a statistically significant difference was established in the mean drop values in the plaque $\mathrm{pH}$ between group 2 and group $3(\mathrm{p}=$ $0.04)$, between group 2 and group $4(p=0.02)$, between group 2 and group $5(p=0.000)$, between group 3 and group $4(p=0.000)$ and between group 3 and group $5(p=0.000$, Table 3$)$. Among groups 4 and 5 the difference in the mean drop values in the plaque $\mathrm{pH}$ was not statistically significant $(\mathrm{p}>$ 0.05 , Table 3).

Table 3. Comparison between the mean drop values in the plaque $\mathrm{pH}$ between the different groups

\begin{tabular}{|c|c|c|c|c|c|c|}
\hline \multirow{2}{*}{ Time interval } & \multirow{2}{*}{ Group } & \multirow{2}{*}{$\begin{array}{l}\text { Comparison with } \\
\text { group }\end{array}$} & \multirow{2}{*}{$\begin{array}{l}\text { Mean differ- } \\
\text { ences }\end{array}$} & \multicolumn{2}{|c|}{$95 \%$ confidence interval } & \multirow[t]{2}{*}{$\mathbf{P}^{*}$} \\
\hline & & & & Lower limit & Upper limit & \\
\hline \multirow{6}{*}{ 15th $\min$} & \multirow{3}{*}{2} & Group 3 & 0,48 & 0,23 & 0,73 & $=0,000$ \\
\hline & & Group 4 & $-0,06$ & $-0,31$ & 0,19 & $=0,635$ \\
\hline & & Group 5 & $-0,22$ & $-0,47$ & 0,03 & $=0,084$ \\
\hline & \multirow[t]{2}{*}{3} & Group 4 & $-0,54$ & $-0,79$ & $-0,29$ & $=0,000$ \\
\hline & & Group 5 & $-0,70$ & $-0,95$ & $-0,45$ & $=0,000$ \\
\hline & 4 & Group 5 & $-0,16$ & $-0,41$ & 0,09 & $=0,207$ \\
\hline \multirow{6}{*}{ 30th min } & \multirow{3}{*}{2} & Group 3 & 0,24 & 0,00 & 0,48 & $=0,049$ \\
\hline & & Group 4 & $-0,28$ & $-0,52$ & $-0,04$ & $=0,022$ \\
\hline & & Group 5 & $-0,44$ & $-0,68$ & $-0,20$ & $=0,000$ \\
\hline & \multirow[t]{2}{*}{3} & Group 4 & $-0,52$ & $-0,76$ & $-0,28$ & $=0,000$ \\
\hline & & Group 5 & $-0,68$ & $-0,92$ & $-0,44$ & $=0,000$ \\
\hline & 4 & Group 5 & $-0,16$ & $-0,40$ & 0,08 & $=0,197$ \\
\hline \multirow{6}{*}{ 60th min } & \multirow{3}{*}{2} & Group 3 & $-0,15$ & $-0,34$ & 0,05 & $=0,145$ \\
\hline & & Group 4 & $-0,30$ & $-0,50$ & $-0,10$ & $=0,004$ \\
\hline & & Group 5 & $-0,49$ & $-0,70$ & $-0,28$ & $=0,000$ \\
\hline & \multirow[t]{2}{*}{3} & Group 4 & $-0,15$ & $-0,35$ & 0,05 & $=0,133$ \\
\hline & & Group 5 & $-0,34$ & $-0,55$ & $-0,13$ & $=0,002$ \\
\hline & 4 & Group 5 & $-0,19$ & $-0,40$ & 0,02 & $=0,081$ \\
\hline
\end{tabular}


At the 60th minute a statistically significant difference was established in the mean drop values in the plaque $\mathrm{pH}$ between group 2 and group $4(p=0.004)$, group 2 and group $5(p=0.000)$ and between group 3 and group 5 ( $p=0.002$, Table 3$)$. The established differences in the mean drop values in the plaque $\mathrm{pH}$ among the other groups were not statistically significant $(p>0.05$, Table 3$)$.

Using the recorded data for drop in the plaque $\mathrm{pH}$ for each of the groups with HR intake at each of the time intervals, we illustrated the curve of the changes in the mean values of the $\mathrm{pH}$ in Diagram 2. The homeopathic cough syrup has the biggest drop in the plaque $\mathrm{pH}$, followed by the homeopathic granules and pillules.

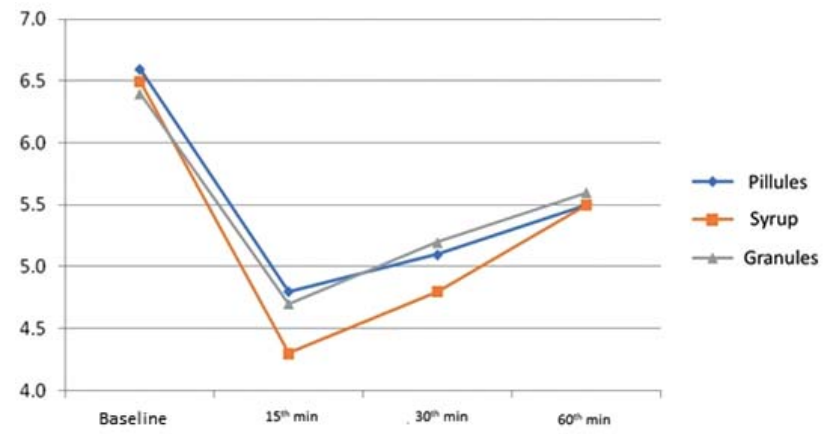

Diagram 2. Curve of changes in the mean values of the plaque $\mathrm{pH}$ at the different time intervals after taking each of the three studied homeopathic remedies

Table 4 shows the number and percentage of the cases with a drop in the plaque $\mathrm{pH}$ from each group based on whether there was a drop below the critical value of 5,5 and between 5,5-6,0.

The majority of cases with a drop in the plaque $\mathrm{pH}$ under the critical value of 5,5 were at the 15 th minute. In group 3 this drop was in $100 \%$ of the cases $(n=$ $25)$. At the 30th minute their number was $20(80 \%)$, and at the 60 th $-5(20 \%)$. In the other groups with HR intake, the cases with a drop in the plaque $\mathrm{pH}$ below 5,5 were about $90 \%$ at the 15 th minute, respectively $92 \%$ in 2nd and 4th group and $88 \%$ - in 5th group (second control group) (Table 4). More cases with a drop in the range of 5,5-6 at the 15th minute were in the 4 th group -3 cases $(12 \%)$, and this tendency continued also at the 30th minute with a total of 12 cases $(48 \%)$. At the 60 th minute more cases with a $\mathrm{pH}$ level drop below 5,5 were observed in the second group - a total of $8(32 \%)$, and between 5,5-6 - in the 3rd group - 14 cases (56\%) (Table 4).

\section{DISCUSSION}

There are numerous publications in the literature on the physicochemical parameters of conventional sugar-containing medications, which contribute to their cariogenic and erosive potential. These are endogenous $\mathrm{pH}$, titratable acidity, soluble substance content, sugar content, viscosity of liquid medications $[1,8,18,28,29,40]$. Apart from these parameters, their frequency, duration and way of administration, as well as their impact on the salivary flow are also of particular importance $[4,20,22,25,26]$. Very little is known about the homeopathic remedies, about the changes in the oral cavity, caused by their intake, about the potential risk they pose in relation to the carious process, especially in childhood. That is why we decided to study the changes in the values of $\mathrm{pH}$ in the dental biofilm after taking some homeopathic remedies due to the simple sugars and/or acids contained in them.

Our study showed that after taking the studied homeopathic remedies, a sharp drop in the plaque $\mathrm{pH}$ was observed in all of the tested samples (individuals), and in a large percentage of the cases it reached below the critical values $(5,5)$ at the 15 th minute interval (Table 4, Diagram 2). At the next set

Table 4. Samples with recorded drop in the plaque $\mathrm{pH}$ by groups and time intervals within the range of 5,5-6 and below 5,5 (by number of samples and \% samples with a drop within the group)

\begin{tabular}{|c|c|c|c|c|c|c|c|c|c|c|c|c|}
\hline \multirow{3}{*}{ Group } & \multicolumn{4}{|c|}{ Drop 15th minute } & \multicolumn{4}{|c|}{ Drop 30th minute } & \multicolumn{4}{|c|}{ Drop 60th minute } \\
\hline & \multicolumn{2}{|c|}{ Below 5,5 } & \multicolumn{2}{|c|}{$5,5-6,0$} & \multicolumn{2}{|c|}{ Below 5,5 } & \multicolumn{2}{|c|}{$5,5-6,0$} & \multicolumn{2}{|c|}{ Below 5,5 } & \multicolumn{2}{|c|}{$5,5-6,0$} \\
\hline & $\begin{array}{c}\mathrm{n}^{*} \text { with } \\
\text { drop }\end{array}$ & $\%$ & $\begin{array}{l}\mathrm{n} \text { with } \\
\text { drop }\end{array}$ & $\%$ & $\begin{array}{c}\mathrm{n} \text { with } \\
\text { drop }\end{array}$ & $\%$ & $\begin{array}{l}\mathrm{n} \text { with } \\
\text { drop }\end{array}$ & $\%$ & $\begin{array}{c}\mathrm{n} \text { with } \\
\text { drop }\end{array}$ & $\%$ & $\begin{array}{l}\mathrm{n} \text { with } \\
\text { drop }\end{array}$ & $\%$ \\
\hline 1 & $n=0$ & 0.0 & $n=0$ & 0.0 & $n=0$ & 0.0 & $\mathrm{n}=0$ & 0.0 & $n=0$ & 0.0 & $n=0$ & 0.0 \\
\hline 2 & $n=23$ & 92.0 & $n=2$ & 8.0 & $n=15$ & 60.0 & $n=10$ & 40.0 & $n=8$ & 32.0 & $n=12$ & 48.0 \\
\hline 3 & $n=25$ & 100 & $n=0$ & 0.0 & $n=20$ & 80.0 & $n=5$ & 20.0 & $n=5$ & 20.0 & $n=14$ & 56.0 \\
\hline 4 & $n=23$ & 92.0 & $n=2$ & 8.0 & $n=14$ & 56.0 & $n=11$ & 44.0 & $n=2$ & 8.0 & $n=15$ & 60.0 \\
\hline 5 & $n=22$ & 88.0 & $n=3$ & 12.0 & $n=10$ & 40.0 & $n=12$ & 48.0 & $n=0$ & 0.0 & $n=10$ & 40.0 \\
\hline
\end{tabular}

$\mathrm{n}^{*}=$ number of samples 
time intervals, a slow recovery of these values was observed. Interestingly, the values of the plaque $\mathrm{pH}$ at the 60th minute after the start of the study did not recover back to the baseline ones in over $90 \%$ of the cases (Table 1). An hour after the start of the study there were individuals with $\mathrm{pH}<5,5$ in groups 2, 3 and 4 , and in all groups with HR intake almost $50 \%$ of the individuals had plaque $\mathrm{pH}$ value in the range of 5,5-6 (Table 4). With remedy 3 (homeopathic syrup) no case of recovery of the baseline $\mathrm{pH}$ was observed at the 60 th minute, while $20 \%$ of the individuals in the group showed plaque $\mathrm{pH}<5,5$ (Table 1 and 4). It is a wellknown fact that the speed, frequency and duration of the drop in the plaque $\mathrm{pH}$ create a cariogenic situation $[23,24]$. There are three great daily drops in the values of the plaque acidity below the critical $\mathrm{pH} 5.5$, connected with the three main meals. If there are also additional ones, it means that the time during which the buffering of the saliva is limited will increase and it could not normalise the $\mathrm{pH}$ of the dental biofilm. Long periods of acidic environment and short periods for recovery are created this way. In these cases, $\mathrm{pH}$ never recovers to normal values. Thus, teeth cannot remineralise or restore the lost mineral after the initial demineralisation. This creates a greater risk for development of a carious process [25]. In this respect, we can assume that the drop in $\mathrm{pH}$ of the plaque after taking homeopathic remedies, due to the simple sugars and/or acids content in them, could also prove risky for initiating a carious process. According to our study at the 15th minute plaque $\mathrm{pH}$ values of 5,5 and below were observed in almost all of the tested groups and individuals who took a homeopathic remedy, containing sugars and/or acids (Table 4). This means that after each intake of these homeopathic remedies an acidic environment was created on the enamel surface due to the simple sugars and/or acids contained in them, and which is maintained for a long period of time, sometimes even for more than an hour - in groups 2, 3 and 4 (Table 1).

We attribute the obtained results to the specific characteristics of the homeopathic remedies, very similar to the conventional ones. Firstly, this is the sugar content in this type of alternative medications. Most commonly, this is sucrose (which is present in the remedies studied by us, according their composition). It is considered to be more cariogenic than the other sugars, even more than the monosaccharides [2628]. The production of acids during the fermentation of sucrose disturbs the balance of the microbial community by stimulating the growth of cariogenic species [29]. Studies demonstrate that sucrose causes a higher mineral loss than glucose and fructose [27], induces lower levels of $\mathrm{pH}$, higher microbial number of mutans streptococci and greater demineralisation in comparison with starch [30]. It is established that DMFT increases by 0.09 units per every $10 \mathrm{gr}$ additionally consumed sugars [15]. For the homeopathic remedies, it is established that 5 pillules administered 4 times daily contain 1 gram of sugar in total [31].

Additionally the environment in the biofilm could be acidified due to the low endogenous $\mathrm{pH}$ and the high titratable acidity of the medicine [8, 3234]. Some authors have estimated that the plaque $\mathrm{pH}$ changes in children after taking 6 conventional paediatric medications [35]. They established a considerable drop in the plaque $\mathrm{pH}$ after the intake of the medications. Researchers claim particular food or a product is considered acidogenic when it leads to a $\mathrm{pH}$-response similar to that after rinsing with a $10 \%$ sucrose solution. They showed that the studied drugs, containing sucrose, produce significantly low levels of $\mathrm{pH}$ of the plaque, which do not differ from those after intake of sucrose. Therefore, these drugs are acidogenic. Rekola also finds a pronounced drop in the plaque $\mathrm{pH}$ after intake of conventional medications (CM) [36]. The results obtained by us regarding a drop in the plaque $\mathrm{pH}$, but after taking homeopathic remedies, are similar to those of Rekola. In our study we found the highest mean values of drop in the group taking the homeopathic syrup (at the 15th and the 30th minute), and at the 15 th minute the level of the drop in the $\mathrm{pH}$ of the plaque after taking the other homeopathic remedies is comparable to that after intake of a $10 \%$ sucrose solution (Table 2, Diagram 1). In the following time intervals, it appears that the intake of sucrose solution results in the least drop in the plaque $\mathrm{pH}$ or in equal to the one after intake of homeopathic granules. These conclusions support the results from similar research on CM [36]. They also confirm our hypothesis that the intake of these medications, due to their sugar and acid content, leads to a rapid drop in the plaque $\mathrm{pH}$ under its critical values, which is maintained for a long period of time.

The highest mean drop level in the plaque $\mathrm{pH}$ was established after taking the homeopathic cough syrup (group 3) at 15 th minute $(-2,24)$ and at 30th minute $(-1,72)$. The drop was lower for the other studied remedies (Table 2 and Diagram 1). We established a statistically significant difference in the mean drop value of the plaque $\mathrm{pH}$ between group 3 and the other groups at the 15th minute after the start of the study (Table 2). This is probably due to the consistency of the antitussive syrup. It is a proved fact that viscous liquids adhere to the teeth and the inner surfaces of the oral cavity and therefore remain in 
the mouth for a longer period of time. This increases their local damaging effects $[37,38]$. Research has shown that viscous syrups with an extended oral clearance can prove risky for the dental health since they result in demineralisation of the enamel $[1,5$, $22,39]$. An additional aggravating factor is the fact that children lack a steady habit and ability to remove the food residues from their mouth after eating or drinking [40].

In our study we demonstrated a drop in the plaque $\mathrm{pH}$ value in $100 \%$ of the children after taking tested homeopathic remedies, and in a large percentage of the cases this drop was below the critical value at the 15th and the 30th minute (Table 1 and 4). Quite interestingly, the drop in the plaque $\mathrm{pH}$ remains for a long period of time even an hour later, without recovering to the baseline values. This fact does not coincide with the knowledge that after intake of simple carbohydrates there is a sharp drop in the plaque $\mathrm{pH}$ from 6.5 to 5.1 and a slow increase to the baseline value, requiring between 15 and 40 minutes [41]. This new information means that there will be a longer disbalance between the processes of de- and re-mineralisation on the enamel surface. On the other - due to the absence of a recovered baseline plaque $\mathrm{pH}$ level, this would condition an even faster start of the demineralising processes after a consecutive intake of simple carbohydrates.

We find our results alarming due to the fact that the potential prolonged and frequent intake of homeopathic remedies could lead to initiation of a carious process in childhood because of the simple sugars and/or acids contained in them. This would be facilitated due to the intake specificity of this type of medications - often during the day (in most of the cases even more than 3 times per day), placing them in the mouth for a few minutes between meals, sometimes without the possibility to rinse the mouth with water immediately after intake. We believe that, due to this risk, children with frequent intake of homeopathic remedies containing sugars and/or acids should be subject to specific monitoring and programs for oral prophylaxis.

\section{CONCLUSIONS}

The intake of the tested homeopathic remedies, containing simple sugars and/or acids leads to a sharp drop in the plaque $\mathrm{pH}$ in all of the tested samples (individuals) at the 15th minute, and in a significant number of the cases this drop is below the critical $\mathrm{pH}$ values.

In over $90 \%$ of the cases, the plaque $\mathrm{pH}$ values did not recover to the baseline ones by the 60th minute after intake of these homeopathic remedies, and some remain below the critical $\mathrm{pH}$ levels.

With one of the remedies - a liquid homeopathic remedy, there were no cases of restoring the baseline values of $\mathrm{pH}$ at the 60th minute.

The specificity of the intake of homeopathic remedies (often during the day - over 3 times daily, their retention in the mouth, without the possibility for rinsing with water) and the sharp and prolonged drop in the plaque $\mathrm{pH}$ which their intake causes, creates conditions for an increased risk for carious process development, due to the simple sugars and/or acids contained in them.

Disclosure summary: The authors have nothing to disclose.

\section{REFERENCES}

1. Maguire A, Baqir W, Nunn J. Are sugars-free medicines more erosive than sugars-containing medicines? An in vitro study of paediatric medicines with prolonged oral clearance used regularly and long-term by children. Int J Paediatr Dent, 2007, 17(4), 231-238.

2. Marquezan M, Pozzobon R, Oliveira M. Medicines used by pediatric dentistry patients and its cariogenic potential. Rev Pos-Grad, 2007, 13, 334-339.

3. Nankar M, Walimbe $\mathrm{H}$, Bijle $\mathrm{M}$ et al. Comparative evaluation of cariogenic and erosive potential of commonly prescribed pediatric liquid medicaments: An in vitro study. J Contemp Dent Pract, 2014, 15(1), 20-25.

4. Pierro $\mathrm{V}$, Abdelnur $\mathrm{J}$, Maia $\mathrm{L}$ et al. Free sugar concentration and $\mathrm{pH}$ of paediatric medicines in Brazil. Community Dent Health, 2005, 22(3), 180-183.

5. Saeed S, Bshara N, Trak J et al. An in vitro analysis of the cariogenic and erosive potential of pediatric liquid analgesics. J Indian Soc Pedod Prev Dent, 2015, 33(2), 143-146.

6. Sahgal J, Sood P, Raju O. A comparison of oral hygiene status and dental caries in children on long term liquid oral medications to those not administered with such medications. J Indian Soc Pedod Prev Dent, 2002, 20(4), 144-151.

7. Nikiforuk G. Understanding dental caries. Basel, New York: Karger Publishers; 1985, 108-111.

8. Nirmala S, Popuri V, Chilamakuri S et al. Oral health concerns with sweetened medicaments: Pediatricians`acuity. J Int Soc Prevent Communit Dent, 2015, 5, 35-39.

9. Cox E, Halloran D, Homan $S$ et al. Trends in the prevalence of chronic medication use in children: 2002-2005. Pediatrics, 2008, 122, 1053-1061.

10. Headley J, Northstone K. Medication administered to children from 0 to 7,5 years in the Avon Longitudinal Study of Parents and Children (ALSPAC). Eur J Clin Pharmacol, 2007, 63, 189-195.

11. Xavier A, Moura E, Azevedo W et al. Erosive and cariogenicity potential of pediatric drugs: study of physicocechmical parameters. BMC Oral Health, 2013, 13, 71.

12. Free library [Internet]. Alternative medicine [updated 2009 January 1; cited 2016 September 13]. Allopathic medicine for dental professional; [abou 8 screens]. Available from http:// www.thefreelibrary.com 
13. Bhat S, Sargod S, George D. Dentistry and homeopathy: an overview. Dent Update, 2005, 32(8), 486-488.

14. Anderson $\mathrm{P}$, Hector $\mathrm{M}$, Rampersad $\mathrm{M}$. Critical $\mathrm{pH}$ in resting \& stimulated whole saliva in groups of children \& adults. Int $\mathrm{J}$ Ped Dent, 2011, 11, 266-273.

15. Bernabé $E$, Vehkalahti M, Sheiham A et al. The shape of the dose-response relationship between sugars and caries in adults. J Dent Res, 2016, 95(2), 167-172.

16. Dodwad V, Malhotra S, Nayyar N. Toothpaste wars: To assess the efficacy of a herbal, homeopathic and a conventional toothpaste in the control of plaque and gingivitis - A clinicobiochemical study. Indian J Stomatol, 2011, 2(2), 91-94.

17. Subramaniam $\mathrm{P}$, Kumar $\mathrm{K}$. Change in salivary $\mathrm{pH}$ following use of homeopathic medicines: A preliminary study. Eur $\mathrm{J}$ Gen Dent, 2013, 2(1), 31-36.

18. Cavalcanti A, Fernandes L, Barbosa A et al. pH, titratable acidity and total soluble solid content of pediatric antitussive medicines. Acta Stomatol Croatica, 2008, 42, 164-170.

19. Cavalcanti $A$, Sousa $R$, Clementino $M$ et al. In vitro analysis of the cariogenic and erosive potential of paediatric antitussive liquid oral medications. Tanz J Health Res, 2012, 14, 1-8.

20. Nunn J, Ng S, Sharkey I et al. The dental implications of chronic use of acidic medicines in medically compromised children. Pharm World Sci, 2001, 23, 118119.

21. Passos I, Sampaio F, Martínez $C$ et al. Sucrose concentration and $\mathrm{pH}$ in liquid oral pediatric medicines of longterm use for children. Rev Panam Salud Publica, 2010, 27, 132137.

22. Subramaniam $P$, Nandan N. Cariogenic potential of pediatric liquid medicaments - An in vitro study. J Clin Pediatr Dent, 2012, 36(3), 357-362.

23. Featherstone J. Diffusion phenomena and enamel caries development. In: "Cariology Today. International Congress in honour of Professor Dr. H.R. Mühlemann”. Zurich 1983. Basel: Karger; 259-268.

24. Fejerskov O, Kidd E, Nyvad B. Dental caries: the disease and its clinical management -2 nd edition. Blackwell Monksgaard 3-6; 19-48; 2008, 161-230.

25. Pitts N, Zero D, Marsh P et al. Dental caries Nature Reviews. Disease Primers 3:article number 17030, 2017.

26. Birkhed D, Frostell G, Lamm C. Cariogenicity of glucose, sucrose and amylopectin in rats and hamsters infected and noninfected with Streptococcus mutans. Caries Res, 1980, 14, 441-447.
27. Cury J, Rebelo M, Del Bel Cury A et al. Biochemical composition and cariogenicity of dental plaque formed in the presence of sucrose or glucose and fructose. Caries Res, 2000, 34, 491-497.

28. Ribeiro C, Tabchoury C, Del Bel Cury A et al. Effect of starch on the cariogenic potential of sucrose. Br J Nutr, 2005, 94, 44-50.

29. Marsh P. Sugar, fluoride, $\mathrm{pH}$ and microbial homeostasis in dental plaque. Proc Finn Dent Soc, 1991, 87, 515-525.

30. Klein M, Hwang G, Santos $P$ et al. Streptococcus mutans derived extracellular matrix in cariogenic oral biofilms. Frontiers in Cellular and Infection Microbiology 5: Article 10, 2015.

31. Hahnemann S. Organon of the Medical Art. Edited by O'Reilly W. Palo Alto, California (USA): Birdcage Books, 1996, 232-245.

32. Babu K, Rai K, Hegde A. pH of medicated syrups - does it really matter? - an in vitro study: Part-II151. J Clin Pediatr Dent, 2008, 33(2), 137-142.

33. Greenwood M, Feigal R, Messer H. Cariogenic potential of liquid medications in rats. Caries Res, 1984, 18, 447-449.

34. Kenny D, Somaya P. Sugar load of oral liquid medications on chronically ill children. J Can Dent Assoc, 1989, 55, 4346.

35. Sunitha S, Prashanth G, Shanmukhappa et al. An analysis of concentration of sucrose, endogenous $\mathrm{pH}$, and alteration in the plaque $\mathrm{pH}$ on consumption of commonly used liquid pediatric medicines. J Ind Soc Pedod Prevent Dent, 2009, 27(1), 44-48.

36. Rekola M. In vivo acid production from medicines in syrup form. Caries Res, 1989, 23, 412416.

37. Cairns A, Watson M, Creanor S et al. The $\mathrm{pH}$ and titratable acidity of a range of diluting drinks and their potential effect on dental erosion. J Dent, 2002, 30, 313-317.

38. Valinoti A, da Silva Pierro V, da Silva E et al. In vitro alterations in dental enamel exposed to acids medicines. Int $\mathrm{J}$ Paed Dent, 2011, 21, 141-150.

39. Neves B, Farah A, Lucas E et al. Are paediatric medicines risk factors for dental caries and dental erosion?. Community Dent Health, 2010, 27, 46-51.

40. Crossner C, Hase J, Birkhed D. Oral sugar clearance in children compared with adults. Caries Res, 1991, 25(3), 201-206.

41. Stephan R, Miller B. A quantitative method for evaluating physical and chemical agents which modify production of acids in bacterial plaques on human teeth. J Dent Res, 1943, $22,45-51$. 